\title{
Diagnóstico de criptosporidiose em amostras fecais de bezerros por imunofluorescência direta e microscopia de contraste de fase
}

\author{
Diagnosis of cryptosporidiosis in fecal samples of calves using direct immunofluorescence \\ and phase contrast microscopy
}

\author{
Weslen Fabricio Pires Teixeira' ${ }^{\mathrm{I}}$ William Marinho Dourado Coelho ${ }^{\mathrm{II}}$ \\ Ricardo Velludo Gomes de Soutello ${ }^{\mathrm{III}}$ Fernando Paes de Oliveira ${ }^{\mathrm{III}}$ Camila Guariz Homem \\ Cáris Maroni Nunes ${ }^{\mathrm{I}}$ Marcelo Vasconcelos Meireles ${ }^{\mathrm{I}^{*}}$
}

RESUMO

O presente estudo teve como objetivo comparar as técnicas de imunofluorescência direta (IFD) e a microscopia de contraste de fase em solução de Sheather (MCF), para detecção de oocistos de Cryptosporidium spp. em amostras fecais de bezerros. A determinação dos limiares detecção da IFD e da MCF foi realizada utilizando cinco alíquotas de uma amostra fecal de bezerro, comprovadamente negativa para Cryptosporidium spp., adicionadas com diferentes quantidades de oocistos de Cryptosporidium parvum. Ao exame das 5 alíquotas, a IFD e a MCF apresentaram, respectivamente, limiares de detecção de $3,3 \times 10^{4}$ (duas alíquotas positivas) e $3,3 \times 10^{5}$ oocistos (1 alíquota positiva) por grama de fezes. Foram também realizadas a comparação entre a positividade obtida e uma análise semiquantitativa do número de oocistos observados por campo de microscopia, em ambos os métodos, em 300 amostras fecais de bezerros. Entre as 300 amostras, $19,7 \%$ (59/300) foram positivas pela IFD, com diferença estatisticamente significante $(P=0,0098)$ quando comparada com a positividade obtida pela MCF, que foi de 11,7\% (35/ 300). As amostras positivas foram submetidas à reação em cadeia da polimerase para amplificação de fragmentos da subunidade $18 S$ do rRNA, com posterior sequenciamento dos fragmentos amplificados, o que permitiu a identificação de Cryptosporidium andersoni em 11,9\% (7/59) e de C.parvum em $88,1 \%$ (52/59) das amostras. Os resultados observados comprovam que a IFD foi mais eficiente que a MCF para detecção de oocistos de Cryptosporidium spp. em amostras fecais de bezerros.

Palavras-chave: Cryptosporidium spp., oocistos, fezes, Sheather.

\section{ABSTRACT}

This study aimed to compare the direct immunofluorescence assay (DIF) and the phase contrast microscopy in Sheather solution (PCM) for detection of Cryptosporidium oocysts in fecal samples from calves. The determination of the thresholds of detection of DIF and PCM was performed using five aliquots of a fecal sample from a calf negative for Cryptosporidium spp. oocysts, spiked with different amounts of Cryptosporidium parvum oocysts. The screening of the five aliquots revealed that the DIF and MCF showed respectively, detection thresholds of $3.3 \times 10^{4}$ ( 2 positive aliquots) and $3.3 \times 10^{5}$ (1 positive aliquot) oocysts per gram of fecal sample. Further analyses were accomplished in order to compare the positivity results and to determine semiquantitatively the number of oocysts per field of microscopy, in both methods, in 300 fecal samples from calves. Among the 300 samples, $19.7 \%$ (59/300) were positive by DIF, result that was statistically significant $(P=0.0098)$ when compared with the positivity obtained by the PCM, which was $11.7 \%$ (35/300). The positive samples were submitted to the nested-PCR assay for amplification of fragments of the 18S subunit of rRNA, following sequencing of amplified fragments, allowing the identification of Cryptosporidium andersoni in $11.9 \%(7 / 59)$ and $\mathbf{C}$. parvum in $88.1 \%$ (52/59) of the samples. The present results indicate that the DIF was more effective than PCM in the detection of Cryptosporidium in fecal samples from calves.

Key words: Cryptosporidium spp., oocysts, feces, Sheather.

\section{INTRODUÇÃO}

Parasitos do gênero Cryptosporidium são coccídios reconhecidos como importantes patógenos causadores de diarréia em vertebrados, incluindo bovinos e o homem (FAYER et al., 2000). Em bovinos, os bezerros neonatos são mais suscetíveis à infecção clínica, sendo os animais adultos acometidos por infecções de

IFaculdade de Medicina Veterinária, Universidade Estadual Paulista (UNESP), Rua Clóvis Pestana, 793, 16050-680, Bairro Dona Amélia, Araçatuba, SP, Brasil. E-mail: marcelo@fmva.unesp.br. *Autor para correspondência.

IFaculdade de Ciências Agrárias e Veterinárias, UNESP, Jaboticabal, SP, Brasil.

${ }^{\text {IIIC } C u r s o ~ d e ~ M e d i c i n a ~ V e t e r i n a ́ r i a, ~ F u n d a c ̧ a ̃ o ~ E d u c a c i o n a l ~ d e ~ A n d r a d i n a, ~ A n d r a d i n a, ~ S P, ~ B r a s i l . ~}$ 
natureza assintomática ou associadas a sintomas clínicos de pouca gravidade (O’DONOGHUE, 1995). Os bovinos podem ainda atuar como reservatórios de Cryptosporidium parvum, espécie que apresenta potencial zoonótico (FAYER et al., 2000).

Em pesquisas realizadas no Brasil, utilizando amostras fecais de bovinos de até 90 dias de idade, foi constatada ocorrência de Cryptosporidium sp. de 0,6 a $72,1 \%$, em muitos casos com presença de diarréia, associada ou não a outros agentes etiológicos (GARCIA \& LIMA, 1994; SOUZA \& LOPES, 1995; FEITOSA etal., 2004; LANGONI etal., 2004; OLIVEIRAFILHO et al., 2007; CARDOSO et al., 2008; FEITOSA et al., 2008).

Inúmeros métodos foram desenvolvidos para diagnóstico de criptosporidiose, sendo as técnicas que envolvem a detecção direta do parasito, por observação microscópica, as mais comumente utilizadas na rotina laboratorial (JEX et al., 2008). No entanto, essas técnicas podem apresentar resultados falsopositivos e baixa sensibilidade (ARROWOOD \& STERLING, 1989; CASEMORE, 1991), além de promoverem alterações na morfologia e morfometria dos oocistos (MEIRELES \& FIGUEIREDO, 1992).

O objetivo deste experimento foi comparar a técnica de imunofluorescência direta (IFD), realizada com conjugado contendo anticorpos policlonais antiC. parvum, e a microscopia com contraste de fase em solução de Sheather (MCF), para detecção de oocistos de Cryptosporidium sp. em amostras fecais de bezerros com faixa etária entre uma semana e quatro meses de idade.

\section{MATERIAL E MÉTODOS}

Os limiares de detecção da IFD e da MCF foram determinados a partir de uma amostra fecal não diarréica de um bezerro com quatro meses de idade, comprovadamente negativa para Cryptosporidium spp., por meio de MCF e da reação em cadeia da polimerase (nested $\mathrm{PCR}$ ) para amplificação de fragmentos da subunidade 18S do rRNA (XIAO et al., 2000). Foram preparadas cinco alíquotas de $3 \mathrm{~g}$, adicionadas de $10^{2}, 10^{3}, 10^{4}, 10^{5}$ e $10^{6}$ oocistos de $\boldsymbol{C}$. parvum e posteriormente submetidas à centrífugosedimentação em água éter (MELONI \& THOMPSON, 1996). A partir de cada alíquota, foram feitas dez lâminas: cinco para exame por IFD e cinco para MCF. Em cada lâmina, foram visualizados 80 campos de microscopia (aumento de 400x), totalizando 400 campos por alíquota.

Em outro momento, foi realizada a detecção de oocistos de Cryptosporidium spp., por IFD e MCF, em 300 amostras fecais de bezerros, com faixa etária de 1 semana a 4 meses de idade, provindas de 37 propriedades leiteiras de municípios da região noroeste do Estado de São Paulo. As amostras fecais foram submetidas à centrífugo-sedimentação em água/éter e divididas em duas alíquotas, sendo que uma foi diluída em formol tamponado 10\% (proporção de 1:3), para utilização em IFD, e a outra em bicromato de potássio $5 \%$ (proporção de 1:3), posteriormente utilizada em MCF. As alíquotas diluídas foram armazenadas a $4^{\circ} \mathrm{C}$, até o momento da análise.

As lâminas utilizadas para IFD foram previamente tratadas com polilisina diluída na proporção de 1:20 em água deionizada (ARROWOOD et al., 1991). Sobre a lâmina, foram adicionados $25 \mu \mathrm{L}$ da amostra diluída em formol, deixando secar totalmente em temperatura ambiente. Após, foram adicionados $25 \mu \mathrm{L}$ do conjugado composto por IgG policlonal de coelho anti-C. parvum marcada com isotiocianato de fluoresceína (produzido no laboratório de Ornitopatologia da UNESP, campus de Araçatuba, SP) diluído na proporção de 1:80 em PBS 0,01M, pH 7,2 e 4,6-diamidino-2-phenilindole - DAPI, $(50 \mu \mathrm{L}$ de DAPI a $2 \mathrm{mg} \mathrm{mL}^{-1}$ para $50 \mathrm{~mL}$ de PBS 0,01M, pH 7,2), com incubação da lâmina a $37^{\circ} \mathrm{C}$, por $30 \mathrm{~min}$, em câmara úmida. Ao término da incubação, foi realizada uma lavagem com PBS 0,01M, pH 7,2, finalizando a montagem com uma lamínula sobre $25 \mu \mathrm{L}$ do tampão de montagem (glicerol 90\% em PBS 0,01M, pH 7,2; pphenylenediamine a $0,1 \mathrm{mg} \mathrm{mL}^{-1}$. A visualização dos oocistos foi feita em um microscópio Olympus BX-50, com lâmpada de mercúrio de $100 \mathrm{~W}$, filtros U-MWU2 (DAPI) e U-MWU2-B (fluoresceína), em aumento de 400x. A reação foi considerada positiva quando foi observada fluorescência de cor verde brilhante, emitida principalmente da parede de estruturas com morfologia e morfometria compatíveis com oocistos de Cryptosporidium spp., eventualmente com evidenciação de sutura.

Para preparação das lâminas utilizadas para MCF, os sedimentos fecais foram lavados por centrifugação com água deionizada para retirada do bicromato de potássio e, posteriormente, diluídos nesse mesmo tipo de água, na proporção de 1:3. Sobre cada lâmina, foram adicionados $25 \mu \mathrm{L}$ da amostra e $25 \mu \mathrm{L}$ de solução de Sheather, homogeneizando e finalizando a montagem com uma lamínula. As lâminas foram consideradas positivas quando estruturas com morfologia e morfometria compatíveis com oocistos de Cryptosporidium spp. foram visualizadas como estruturas com brilho característico, contra um fundo escuro, eventualmente com pontos escuros em seu interior. A visualização dos oocistos foi realizada em um microscópio Olympus BX-50, com objetiva de contraste de fase, em aumento de 400x. 
Ambas as técnicas (IFD e MCF) foram realizadas em duplicata, com observação de 400 campos de microscopia por lâmina. A positividade das amostras fecais foi confirmada de acordo com SMITH et al. (2002), por meio de visualização das estruturas internas dos oocistos em microscopia com contraste diferencial de fase (Nomarsky) ou por visualização do núcleo dos esporozoítos corados com DAPI. Em todas as amostras positivas na IFD e/ou MCF, foram realizadas análises semiquantitativas do número de oocistos observados por campo de microscopia (aumento de 400x), segundo protocolo descrito por FÉRES et al. (2009), com algumas modificações: escore 1 (1 a 10 oocistos por lâmina); escore 2 ( 1 a 5 oocistos por campo); escore 3 ( 5 a 20 oocistos por campo) e escore 4 (acima de 21 oocistos por campo).

Para identificação das espécies de Cryptosporidium presentes nas amostras fecais dos bezerros, todas as amostras positivas pela microscopia foram submetidas à extração de DNA (MEIRELES et al., 2007) para realização da nested PCR. Para isso, foram utilizados primers específicos para amplificação de sequência do gene da subunidade $18 \mathrm{~S}$ do rRNA (XIAO et al., 2000) e sequenciamento dos fragmentos amplificados no Centro de Sequenciamento e Genômica Funcional da UNESP, Campus de Jaboticabal, utilizando o "ABI Prism ${ }^{\circledR}$ Dye Terminator 3.1", em sequenciador automático ABI 3730XL. Água ultrapura foi utilizada em lugar de DNA-molde, em reaçõescontrole negativas, e DNA de Cryptosporidium galli foi utilizado como molde em reações-controle positivas.

Foi calculado o intervalo de confiança do número de oocistos de $\boldsymbol{C}$. parvum encontrados nas lâminas de IFD e MCF, preparadas a partir das cinco alíquotas adicionadas de oocistos. Para determinação da significância estatística dos resultados de positividade e do número de oocistos observados nas diferentes alíquotas, quando submetidas às duas técnicas de diagnóstico, foram utilizados, respectivamente, o teste exato de Fisher e o teste $t$ de Student. O teste de Qui-Quadrado $\left(\mathrm{x}^{2}\right)$ foi aplicado para verificar a significância estatística entre a positividade obtida pela IFD e MCF em amostras fecais de bezerros e o índice Kappa (K) foi determinado para verificar a concordância entre os dois testes.

\section{RESULTADOS E DISCUSSÃO}

A MCF é pouco utilizada para pesquisa de oocistos de Cryptosporidium spp. em amostras fecais, apesar de ser considerada um método rápido e eficiente e de não promover alterações na morfologia e morfometria dos oocistos, o que pode ser observado em técnicas de coloração (WILSON \& ACRES, 1982;
MEIRELES \& FIGUEIREDO, 1992). Essas técnicas ainda apresentam as desvantagens de baixa sensibilidade e de eventuais resultados falso-positivos (CASEMORE, 1991; WEBER et al., 1991). Devido a essas características, foi realizada a comparação com a IFD, que apresenta melhor sensibilidade e especificidade que as técnicas convencionais de coloração utilizadas para visualização microscópica de oocistos (STIBBS \& ONGERTH, 1986; ARROWOOD \& STERLING, 1989; WEBER et al., 1991; ALLES et al., 1995).

As alíquotas fecais inoculadas com oocistos de $C$. parvum e as amostras de bezerros infectados, quando analisadas pela IFD, apresentaram, respectivamente, limiar de detecção mais baixo e maior positividade que a MCF. Com a utilização dessas técnicas, foi possível obter positividade, respectivamente, em $40 \%$ (2/5) das lâminas contendo $10^{4}$ e em $20 \%(1 / 5)$ das lâminas contendo $10^{5}$ oocistos de C. parvum, em $3 \mathrm{~g}$ de fezes. Os valores de porcentagem de lâminas positivas, o número de oocistos encontrados e o intervalo de confiança, obtidos pela IFD e MCF nas alíquotas fecais inoculadas com oocistos de C. parvum, estão descritos na tabela 1.

As técnicas mais utilizadas para detecção de oocistos de Cryptosporidium spp. em amostras fecais são as de Kinyoun e Ziehl Neelsen modificada, porém apresentam baixa sensibilidade, conforme demonstrado por WEBER et al. (1991), que relataram $100 \%$ de detecção de oocistos de C. parvum na presença de $5 \times 10^{5}$ e $5 \times 10^{4}$ oocistos por grama de fezes humanas não diarréicas, respectivamente, com utilização das técnicas de Kinyoun e imunofluorescência indireta. Na presente pesquisa, a IFD e a MCF apresentaram 100\% de detecção em amostras contendo respectivamente $10^{5}$ e $10^{6}$ oocistos presentes em três gramas de fezes não diarréicas, ou seja, $3,3 \times 10^{4}$ e $3,3 \times 10^{5}$ oocistos por grama de fezes, respectivamente para IFD e MCF (Tabela 1).

Em amostras de fezes de 300 bezerros, foi observada positividade em 19,7\% (59/300) das amostras, sendo $11,7 \%(35 / 300)$ positivas em ambas as técnicas e $8 \%(24 / 300)$ positivas apenas pela IFD, com diferença estatisticamente significativa pelo teste de Qui-Quadrado $(\mathrm{P}<0,05)$. Esse resultado demonstra que a imunofluorescência de fato apresenta maior sensibilidade que técnicas não imunológicas de visualização microscópica (ALLES et al., 1995; JOHNSTON et al., 2003).

$\mathrm{O}$ grau de concordância entre os resultados da IFD e MCF foi de $92 \%$ ( $\mathrm{K}=0,7$, nível de confiança= 95\%), considerado como bom (CONRATHS \& SCHARES, 2006). O cálculo da especificidade e sensibilidade dos dois métodos não foi realizado devido 
Tabela 1 - Porcentagem de positividade, média, total de oocistos observados e intervalo de confiança calculado para as cinco repetições de cada alíquota de amostras fecais adicionadas de oocistos, em lâminas examinadas por imunofluorescência direta (IFD) e microscopia de contraste de fase (MCF).

\begin{tabular}{|c|c|c|c|c|c|c|}
\hline & & \multicolumn{4}{|c|}{ - } & \multirow{2}{*}{ Total } \\
\hline & & escore 1 & escore 2 & escore 3 & escore 4 & \\
\hline \multirow{5}{*}{ IFD } & escore 1 & $8,6(3)^{* *}$ & - & - & $2,9(1)$ & 11,4 (4) \\
\hline & escore 2 & $11,4(4)$ & $11,4(4)$ & - & - & $22,9(8)$ \\
\hline & escore 3 & $8,6(3)$ & $20(7)$ & $2,9(1)$ & - & $31,4(11)$ \\
\hline & escore 4 & - & $17,1(6)$ & $11,4(4)$ & $5,7(2)$ & $34,3(12)$ \\
\hline & Total & $28,6(10)$ & $48,6(17)$ & $14,3(5)$ & $8,6(3)$ & $100(35)$ \\
\hline
\end{tabular}

a Apresenta diferença estatisticamente significante entre o número de oocistos encontrados na IFD e na MCF (P<0,0001), pelo teste t.

${ }^{\mathrm{b}}$ Apresenta diferença estatisticamente significante entre a positividade obtida na IFD e na MCF $\left.\mathrm{P}<0,05\right)$, pelo teste de Fisher. IC: Intervalo de Confiança com nível de significância de $95 \%$.

à não utilização, neste experimento, de um teste considerado como padrão ouro. No entanto, em comparação com a IFD, verificou-se que a $\mathrm{MCF}$ apresentou sensibilidade mais baixa, porém, especificidade de $100 \%$, evidenciando a sua confiabilidade para utilização em diagnóstico de criptosporidiose, quando não é necessário um teste que tenha a característica de alta sensibilidade, particularmente em amostras com grande quantidade de oocistos.

Por meio da nested PCR e sequenciamento dos fragmentos amplificados, foi constatada a presença de C. parvum em 88,1\% (52/59) e de Cryptosporidium andersoni em 11,9\% (7/59) das amostras positivas. Diversos autores também relataram que $C$. parvum é a espécie mais frequentemente encontrada em bezerros nos primeiros meses de vida (GEURDEN et al., 2006; COKLIN et al., 2009; KESHAVARZ et al., 2009). Apesar de $C$. andersoni não ser encontrado com mais frequência em bezerros nas primeiras semanas de vida, SANTÍN et al. (2004), KVÁC et al. (2006) e SEVÁ et al.
(2010) também descreveram sua presença em amostras fecais de bezerros dessa faixa etária. As amostras que continham oocistos de $\boldsymbol{C}$. andersoni foram positivas somente pela IFD, o que sugere que a visualização de oocistos de C. andersoni em solução de Sheather é menos eficiente para diagnóstico dessa espécie do que para o diagnóstico de C. parvum, conforme demonstrado por KVÁC et al. (2003).

Os resultados da análise semiquantitativa dos oocistos de $\boldsymbol{C}$. parvum, presentes nas lâminas simultaneamente positivas na IFD e MCF estão relacionados na tabela 2 . Na comparação dos escores de oocistos, observou-se que a IFD possibilitou a detecção de um maior número de oocistos por campo que a MCF. A análise semiquantitativa dos oocistos de $\boldsymbol{C}$. andersoni e $\boldsymbol{C}$. parvum, presentes nas lâminas que foram positivas somente pela IFD, está descrita na tabela 3. Nas amostras de bezerros, foi obtida, pela $\mathrm{MCF}$, maior positividade naquelas que continham maiores escores de oocistos (Tabela 2), fato que não se repetiu nas lâminas com menores escores, nas quais a IFD apresentou maior positividade (Tabelas 2 e 3 ).

Tabela 2 - Análise semiquantitativa* de oocistos de C. parvum presentes nas 35 amostras simultaneamente positivas pela imunofluorescência direta (IFD) e microscopia de contraste de fase em solução de Sheather (MCF).

\begin{tabular}{|c|c|c|c|c|c|c|}
\hline & & escore 1 & escore 2 & escore 3 & escore 4 & Total \\
\hline \multirow{5}{*}{ IFD } & escore 1 & $8,6(3)^{* *}$ & - & - & $2,9(1)$ & $11,4(4)$ \\
\hline & escore 2 & $11,4(4)$ & $11,4(4)$ & - & - & $22,9(8)$ \\
\hline & escore 3 & $8,6(3)$ & $20(7)$ & $2,9(1)$ & - & $31,4(11)$ \\
\hline & escore 4 & - & $17,1(6)$ & $11,4(4)$ & $5,7(2)$ & $34,3(12)$ \\
\hline & Total & $28,6(10)$ & $48,6(17)$ & $14,3(5)$ & $8,6(3)$ & $100(35)$ \\
\hline
\end{tabular}

*Escore 1: 1 a 10 oocistos por lâmina; escore 2: 1 a 5 oocistos por campo em aumento de 400x; escore 3: 5 a 20 oocistos por campo em aumento de 400x e escore 4: acima de 21 oocistos por campo em aumento de 400x.

**\% (número de amostras positivas).

Ciência Rural, v.41, n.6, jun, 2011. 
Tabela 3 - Análise semiquantitativa* de oocistos de C. parvum e C. andersoni presentes nas 24 amostras positivas somente pela imunofluorescência direta (IFD).

\begin{tabular}{|c|c|c|c|c|c|}
\hline \multirow{2}{*}{ Espécies } & \multicolumn{5}{|c|}{ 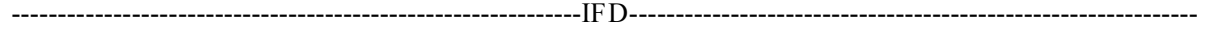 } \\
\hline & escore 1 & escore 2 & escore 3 & escore 4 & Total \\
\hline C. andersoni & $8,6(4 / 7)^{* *}$ & - & $28,6(2 / 7)$ & $14,3(1 / 7)$ & $100(7 / 7)$ \\
\hline C. parvum & $88,2(15 / 17)$ & $5,9(1 / 17)$ & $5,9(1 / 17)$ & - & $100(17 / 17)$ \\
\hline Total & $79,2(19 / 24)$ & $4,2(1 / 24)$ & $12,5(3 / 24)$ & $4,2(1 / 24)$ & $100(24 / 24)$ \\
\hline
\end{tabular}

*Escore 1: 1 a 10 oocistos por lâmina; escore 2: 1 a 5 oocistos por campo em aumento de 400x; escore 3: 5 a 20 oocistos por campo em aumento de 400x e escore 4: acima de 21 oocistos por campo em objetiva de 400x.

** \% (número de amostras positivas/número amostras positivas para C. andersoni ou C. parvum).

\section{CONCLUSÃO}

A IFD apresentou limiar de detecção mais baixo que a MCF, tanto em amostras inoculadas com oocistos como em amostras de bezerros. A MCF pode ser utilizada para diagnóstico de criptosporidiose em amostras com grande quantidade de oocistos, por ser de baixo custo, rápida e de fácil visualização do parasito. No entanto, em amostras com pequena quantidade de oocistos é recomendada a utilização da IFD, por apresentar limiar de detecção mais baixo, evitando, assim, a ocorrência de diagnóstico falso-negativo.

\section{AGRADECIMENTOS}

À Fundação de Amparo à Pesquisa do Estado de São Paulo (FAPESP), pelo apoio financeiro (processo n. 2008/ 57380-1)

\section{FONTES DE AQUISIÇÃO}

Polilisina, Sigma, Saint Louis, Estados Unidos da América.. 4,6-diamidino-2-phenilindole - DAPI, Sigma, Saint Louis, Estados Unidos da América.

p-phenylenediamine, Sigma, Saint Louis, Estados Unidos da América, Estados Unidos da América.

ABI Prism ${ }^{\circledR}$ Dye Terminator 3.1, Applied Biosystems, Califórnia, Estados Unidos da América.

Seqüenciador automático ABI 3730XL, Applied Biosystems, Califórnia, Estados Unidos da América.

\section{REFERÊNCIAS}

ALLES, A.J. et al. Prospective comparison of direct immunofluorescence and conventional staining methods for detection of Giardia and Cryptosporidium spp. in human fecal specimens. Journal of Clinical Microbiology, v.33, n.6, p.1632-1634, 1995. Disponível em: <http://jcm.asm.org/cgi/ reprint/33/6/1632>. Acesso em 18 jan. 2011.

ARROWOOD, M.J.; STERLING, C.R. Comparison of conventional staining methods and monoclonal antibody-based methods for Cryptosporidium oocyst detection. Journal of Clinical Microbiology, v.27,n.7, p.1490-1495, 1989. Disponível em: <http:// jcm.asm. org/ cgi/ reprint/27/7/1490>. Acesso em 18 jan. 2011.
ARROWOOD, M.J. et al. Immunofluorescent microscopical visualization of trails left by gliding Cryptosporidium parvum sporozoites. Journal of Parasitology, v.77, n.2, p.315-317, 1991. Disponível em: <http://www.jstor.org/stable/pdfplus/ 3283104.pdf>. Acesso em: 18 jan. 2011.

CARDOSO, J.M.S. et al. Ocorrência de Cryptosporidium spp. em um rebanho bovino leiteiro no município de Caçapava, estado de São Paulo, Brasil. Revista Brasileira de Parasitologia Veterinária, v.17, supl.1, p.239-242, 2008. Disponível em: <http://www.cbpv.com.br/rbpv/documentos/ 17supl.12008/Protozool011.pdf>. Acesso em: 18 jan. 2011.

CASEMORE, D.P. Laboratory methods for diagnosing cryptosporidiosis. Journal of Clinical Pathology, v.44, n.6, p.445-451, 1991. Disponível em: <http://www.ncbi.nlm.nih.gov/ pmc/articles/PMC496821/pdf/jclinpath00408-0005.pdf $>$. Acesso em: 18 jan. 2011.

COKLIN, T. et al. Prevalence and molecular characterization of Cryptosporidium spp. in dairy calves from 11 farms in Prince Edward Island, Canada. Veterinary Parasitology, v.160, n.3-4, p.323-326, 2009. Disponível em: <http://www.ncbi.nlm.nih.gov/ pubmed/190 70965>. Acesso em: 18 jan. 2011. doi: 10.1016/ j.vetpar. 2008.10.096.

CONRATHS, F.J.; SCHARES, G. Validation of moleculardiagnostic techniques in the parasitological laboratory. Veterinary Parasitology, v.136, p.91-98, 2006. Disponível em: <http://www.ncbi.nlm.nih.gov/pubmed/16414191>. Acesso em: 25 fev. 2011. doi:10.1016/j.vetpar.2005.12.004.

FAYER, R. et al. Epidemiology of Cryptosporidium: transmission, detection and identication. International Journal for Parasitology, v.30, n.12-13, p.1305-1322, 2000. Disponível em: <http://www.ncbi.nlm.nih.gov/pubmed/11113257>. Acesso em: 18 jan. 2011. doi: 10.1016/ S00 20-7519(00)00135-1.

FEITOSA, F.L.F. et al. Prevalência da criptosporidiose em bezerros na região de Araçatuba, Estado de São Paulo, Brasil. Ciência Rural, v.34, n.1, p.189-193, 2004. Disponível em: $<$ http://www.scielo.br/pdf/cr/v34n1/a29v34n1.pdf $>$. Acesso em: 18 jan. 2011.

FEITOSA, F.L.F. et al. Importância de Cryptosporidium spp. como causa de diarréia em bezerros. Pesquisa Veterinária Brasileira, v.28, n.10, p.452-456, 2008. Disponível em: $<$ http://www.scielo.br/pdf/pvb/v28n10/v28n10a02.pdf $>$. Acesso em: 18 jan. 2011.

FÉRES, F.C. et al. Ocorrência e caracterização molecular de Cryptosporidium em cordeiros. Arquivo Brasileiro de 
Medicina Veterinária e Zootecnia, v.61, n.4, p.1002-1005, 2009. Disponível em: <http://www.scielo.br/pdf/abmvz/v61n4/ v61n4a33.pdf>. Acesso em: 18 jan. 2011.

GARCIA, A.M.; LIMA, J.D. Prevalência de Cryptosporidium spp. em rebanhos leiteiros de Pará de Minas (MG) e sua relação com práticas de manejo. Revista Brasileira de Parasitologia Veterinária, v.3, n.1, p.23-28, 1994. Disponível em: <http:/ /www.cbpv.com.br/rbpv/documentos/311994/c3123_28.pdf>. Acesso em: 18 jan. 2011.

GEURDEN, T. et al. Prevalence and genotyping of Cryptosporidium in three cattle husbandry systems in Zambia. Veterinary Parasitology, v.138, n.3-4, p.217-222, 2006. Disponível em: $<$ http://www.ncbi.nlm.nih.gov/pubmed/16546321>. Acesso em: 18 jan. 2011. doi: 10.1016/j.vetpar.2006.02.009.

JEX, R. et al. Cryptosporidium - Biotechnological advances in the detection, diagnosis and analysis of genetic variation. Biotechnology Advances, v.26, n.4, p.304-317, 2008. Disponível em: <http://www.ncbi.nlm.nih.gov/pubmed/18430539>. Acesso em: 18 jan. 2011. doi: 10.1016/j.biotechadv.2008.02.003.

JOHNSTON, S.P. et al. Evaluation of three commercial assays for detection of Giardia and Cryptosporidium organisms in fecal specimens. Journal of Clinical Microbiology, v.41, n.2, p. 623-626, 2003. Disponível em: <http://jcm.asm.org/ cgi/reprint/41/2/623>. Acesso em: 18 jan. 2011. doi: 10.1128/ JCM.41.2.623-626.2003.

KESHAVARZ, A. et al. Prevalence and molecular characterization of bovine Cryptosporidium in Qazvin province, Iran. Veterinary Parasitology, v.160, n.3-4, p.316-318, 2009. Disponível em: $<$ http://www.ncbi.nlm.nih.gov/pubmed/19091477>. Acesso em: 18 jan. 2011 . doi: $10.1016 /$ j.vetpar.2008.11.008.

KVÁC, M. et al. Age-related and housing-dependence of Cryptosporidium infection of calves from dairy and beef herds in South Bohemia, Czech Republic. Veterinary Parasitology, v.137, n.3-4, p.202-209, 2006. Disponível em: <http://www.ncbi.nlm.nih.gov/pubmed/16488542>. Acesso em: 26 fev. 2011.

KVÁC, M. et al. Comparison of selected diagnostic methods for identification of Cryptosporidium parvum and Cryptosporidium andersoni in routine examination of faeces. Journal of Veterinary Medicine, Series B, v.50, n.8, p.405411, 2003. Disponível em: <http://onlinelibrary.wiley.com/ doi/10.1046/j.1439-0450.2003.00694.x/pdf>. Acesso em: 18 jan. 2011. doi: 10.1046/j.1439-0450.2003.00694.x.

LANGONI, H. et al. Contribuição ao estudo da etiologia das diarréias em bezerros de aptidão leiteira no Estado de São Paulo, Brasil. Brazilian Journal of Veterinary Research and Animal Science, v.41, n.5, p.313-319, 2004. Disponível em: <http://www.scielo.br/pdf/bjvras/v41n5/25255.pdf $>$. Acesso em: 18 jan. 2011.

MEIRELES, M.V:; FIGUEIREDO, P.C. Isolamento e identificação do Cryptosporidium baileyi Current et al., 1986 (Apicomplexa: Cryptosporidiidae) em frangos de corte. Revista Brasileira de Parasitologia Veterinária, v.1, n.2, p.125-130, 1992. Disponível em: <http://www.cbpv.com.br/rbpv/documentos/ 121992/c12125_130.pdf>. Acesso em: 18 jan. 2011.

MEIRELES, M.V. et al. Natural infection with zoonotic subtype of Cryptosporidium parvum in capybara (Hydrocoerus hydrochaeris) in Brazil. Veterinary Parasitology, v.147, n.1-2, p.166-170, 2007. Disponível em: <http://www.ncbi.nlm.nih.gov/ pubmed/17467175>. Acesso em: 18 jan. 2011. doi: 10.1016/ j.vetpar.2007.03.034.
MELONI, B.P.; THOMPSON, R.C.A. Simplified methods for obtaining purified oocysts from mice and for growing Cryptosporidium parvum in vitro. Journal of Parasitology, v.82, n.5, p.757-762, 1996. Disponível em: <http:// www.jstor.org/stable/pdfplus/ 3283888.pdf? accept $\mathrm{TC}=$ true $>$. Acesso em: 18 jan. 2011.

O'DONOGHUE, P.J. Cryptosporidium and cryptosporidiosis in man and animals. International Journal for Parasitology, v.25, n.2, p.139-95, 1995. Disponível em: < http://www.ncbi.nlm.nih.gov/ pubmed/7622324 >. Acesso em: 18 jan. 2011. doi: 10.1016/00207519(94)E0059-V.

OLIVEIRA-FILHO, J.P. et al. Diarréia em bezerros da raça nelore criados extensivamente: estudo clínico e etiológico. Pesquisa Veterinária Brasileira, v.27, n.10, p.419-424, 2007. Disponível em: < http://www.scielo.br/pdf/pvb/v27n10/ a06v2710.pdf $>$. Acesso em: 18 jan. 2011.

SANTÍN, M. et al. Prevalence and age-related variation of Cryptosporidium species and genotypes in dairy calves. Veterinary Parasitology, v.122, n.2, p.103-117, 2004. Disponível em: <http:/ /www.ncbi.nlm.nih.gov/pubmed/15177715>. Acesso em: $26 \mathrm{fev}$. 2011. doi:10.1016/j.vetpar.2004.03.020.

SEVÁ, A.P. et al. Occurrence and molecular characterization of Cryptosporidium spp. isolated from domestic animals in a rural area surrounding Atlantic dry forest fragments in Teodoro Sampaio municipality, State of São Paulo, Brazil. Revista Brasileira de Parasitologia Veterinária, v.19, n.4, p.249253, 2010. Disponível em: <http://www.cbpv.com.br/rbpv/ documentos/1942010/rbpv_v19n4_a11.pdf $>$. Acesso em: 16 mar. 2011.

SMITH, H.V. et al. Significance of enhanced morphological detection of Cryptosporidium sp. oocysts in water concentrates determined by using 4,6-Diamidino-2-Phenylindole and immunofluorescence microscopy. Applied and Environmental Microbiology, v.68, n.10, p.5198-5201, 2002. Disponível em: $<$ http://aem.asm.org/cgi/reprint/68/10/5198>. Acesso em: 18 jan. 2011. doi: 10.112 8/AEM.68.10.5198-5201.2002.

SOUZA, J.C.P.; LOPES, C.W.G. Criptosporidiose em bezerros de rebanhos da bacia leiteira Sul-Fluminense, Estado do Rio de Janeiro. Revista Brasileira de Parasitologia Veterinária, v.4, n.1, p.33-36, 1995. Disponível em: <http://www.cbpv.com.br/rbpv/ documentos/411995/c4133_36.pdf>. Acesso em: 18 jan. 2011.

STIBBS, H.H.; ONGERTH, J.E. Immunofluorescence detection of Cryptosporidium oocysts in fecal smears. Journal of Clinical Microbiology, v.24, n.4, p.517-521, 1986. Disponível em: <http:/ jcm.asm.org/cgi/reprint/24/4/517.pdf $>$. Acesso em: 18 jan. 2011.

WEBER R. et al. Threshold of detection of Cryptosporidium oocysts in human stool specimens: evidence for low sensitivity of current diagnostic methods. Journal of Clinical Microbiology, v.29, n.7, p.1323-1327, 1991. Disponível em: $<$ http://www.ncbi.nlm.nih.gov/pmc/articles/PMC270109/pdf/ jcm00043-0059.pdf>. Acesso em: 18 jan. 2011.

WILSON, D.W.; ACRES, S.D. A comparison of dichromate solution flotation and fecal smears for diagnosis of cryptosporidiosis in calves. Canadian Veterinary Journal, v.23, n.8, p.240-246, 1982. Disponível em: <http:// www.ncbi.nlm.nih.gov/pmc/articles/PMC1790179/pdf/ canvetj00285-0018.pdf $>$. Acesso em: 18 jan. 2011.

XIAO, L. et al. Identification of species and sources of Cryptosporidium oocysts in storm waters with a small-subunit rRNA-based diagnostic and genotyping tool. Applied and Environmental Microbiology, v.66, n.12, p.5492-5498, 2000. Disponível em: <http://aem.asm.org/cgi/reprint/66/12/ 5492>. Acesso em: 18 jan. 2011. 